Original

\title{
Immunophenotypical Changes of Myofibroblasts Appearing in Thioacetamide-Induced Hepatic Fibrosis in Rats
}

\author{
Mika Ide $^{1,2}$, Mitsuru Kuwamura ${ }^{1}$, Takao Kotani ${ }^{1}$, and Jyoji Yamate ${ }^{1}$ \\ ${ }^{1}$ Laboratory of Veterinary Pathology, Graduate School of Agriculture and Biological Sciences, Osaka Prefecture \\ University, Gakuencho 1-1, Sakai, Osaka 599-8531, Japan \\ 2 Exploratory Toxicology \& DMPK Research Laboratories, 2-50, Kawaguchishi, 2-Chome, Toda, Saitama 335-8505, \\ Japan
}

\begin{abstract}
Myofibroblasts play important roles in hepatic fibrosis through the production of extracellular matrix. The cells are derived mainly from hepatic stellate cells (HSCs). Immunoexpression of cytoskeletons such as vimentin, desmin, $\alpha$-smooth muscle action ( $\alpha$-SMA) and glial fibrillary acidic protein (GFAP) was analyzed in myofibroblasts appearing in acute type hepatic fibrosis (AHF; $300 \mathrm{mg} / \mathrm{kg}$, a single injection) and chronic type hepatic fibrosis (CHF; $100 \mathrm{mg} / \mathrm{kg}$, twice a week for 10 weeks), which were both induced in F344 rats by thioacetamide. In AHF, the number of vimentin- and desmin-positive cells showed the highest levels on day 3 after the injection, in conformity with an increased number of $\alpha$-SMA-positive myofibroblasts, whereas that of GFAP-positive cells reached a plateau as early as day 1. In CHF, $\alpha$-SMA- and desmin-positive myofibroblasts showed similar kinetics to each other. The numbers gradually increased from weeks 1 to 7 and then expanded quickly at week 10 when pseudolobules were completely developed. On the other hand, the number of vimentin- and GFAP-positive cells in CHF slightly increased at weeks 3 and 4, respectively, and then decreased until week 10. Interestingly, the greatest expression number among these cytoskeletons was vimentin in AHF, whereas it was desmin in CHF. The present study showed that myofibroblasts express various cytoskeletons, and that there is a difference in the expression patterns between AHF and CHF. By RTPCR, nerve growth factor (NGF) mRNA expression markedly increased with time in both AHF and CHF, suggesting that NGF might participate in development of hepatic fibrosis by regulating HSCs with its receptor.

(J Toxicol Pathol 2004; 17: 231-238)
\end{abstract}

Key words: $\alpha$-smooth muscle actin, desmin, GFAP, hepatic fibrosis, hepatic stellate cells, myofibroblasts

\section{Introduction}

In response to hepatocyte injury, hepatic stellate cells (HSCs; Ito cells or perisinusoidal cells) undergo transformation from retinoid-rich pericyte-like cells to myofibroblasts ${ }^{1}$. This process is termed "activation" or "transformation" of HSCs. The transformed HSCs lose their vitamin A store, and acquire morphological features of myofibroblasts that are considered to be cells having an intermediate nature between smooth muscles and fibroblasts ${ }^{1-4}$.

Cytoskeletons such as vimentin, desmin, $\alpha$-smooth muscle actin ( $\alpha$-SMA) and glial fibrillary acidic protein (GFAP) are known to be differentially distributed among various cell types. Generally, vimentin is expressed in cells

Received: 22 July 2004, Accepted: 1 October 2004

Mailing address: Jyoji Yamate, Laboratory of Veterinary Pathology,

Graduate School of Agriculture and Biological Sciences, Osaka

Prefecture University, Gakuencho 1-1, Sakai, Osaka 599-8531, Japan

TEL: 81-722-254-9482 FAX: 81-722-250-7208

E-mail: yamate@vet.osakafu-u.ac.jp of mesenchymal origin: desmin and $\alpha$-SMA in smooth muscle cells, and GFAP in astroglial cells ${ }^{2,5}$. It is known that cytoskeletal features are variously changed in the development of myofibroblasts in fibrotic lesions ${ }^{5,6}$. The spectrum is divided into the following phenotypes: expressing of vimentin, co-expressing vimentin and desmin, co-expressing vimentin and $\alpha$-SMA, and co-expressing vimentin, desmin and $\alpha$-SMA ${ }^{5}$. The transformed HSCs are usually identified by a positive immunoreaction to $\alpha$ $\mathrm{SMA}^{2,4,7}$. Interestingly, GFAP immunoreactivity has been reported to be seen in the perisinusoidal HSCs ${ }^{8}$. Thus, GFAP might be a specific marker for transformed HSCs in hepatic fibrosis ${ }^{3,8}$. Taken together, it is likely that transforming HSCs express various cytoskeletons such as vimentin, desmin, $\alpha$-SMA, and GFAP. However, immunophenotypical changes of HSCs in rat hepatic fibrosis remain to be analyzed in detail.

Recently, we reported thioacetamide (TAA)-induced rat hepatic fibrosis as an animal model ${ }^{9,10}$. Using the TAAinduced rat hepatic fibrosis model, in the present study, we analyzed the immunophenotypes of cytoskeletons in myofibroblasts appearing in fibrotic lesions. In addition, 
mRNA expression of nerve growth factor (NGF) was investigated by reverse transcription polymerase chain reaction (RT-PCR). NGF is a neurotrophic protein essential for the maintenance, growth, and differentiation of nerve cells ${ }^{11,12}$. It was recently reported that during liver fibrogenesis, activated HSCs expressed p75, a low-affinity receptor for NGF, indicating that NGF, a member of the neurotrophin family, may be associated with functional and morphological changes in HSCs through expressed p $75^{13,14}$.

\section{Materials and Methods}

\section{Animal models}

The histopathological characteristics of hepatic fibrosis used in this study have already been reported ${ }^{9,10}$. The models are briefly introduced below. The rat strain used was F344/DuCrj (Charles River Japan; Hino, Shiga, Japan), and the rats were housed in an animal room maintained at $22 \pm$ $4^{\circ} \mathrm{C}$ with a 12 -h light-dark cycle, and fed a standard diet for rats with tap water ad libitum. These experiments complied with our institutional guidelines for animal care.

\section{Acute type hepatic fibrosis (AHF) model}

The production of AHF has been described previously ${ }^{10}$. Briefly, twenty-one rats were injected intraperitoneally with TAA (Wako Pure Chemical, Osaka, Japan) dissolved in $0.9 \% \mathrm{NaCl}$ at a dose of $300 \mathrm{mg} / \mathrm{kg}$ body weight. Three rats were examined on post-single injection (PSI) days 1, 3, 5, 7, 10, 15, and 20. Six rats as controls received an equivalent volume of physiological saline in the same manner, and three rats were examined at 1 and 20 days after the injection.

\section{Chronic type hepatic fibrosis (CHF) model}

The production of CHF has been described previously ${ }^{9}$. In the TAA-treated group, 15 rats were injected intraperitoneally twice a week with TAA dissolved in $0.9 \%$ $\mathrm{NaCl}$ at a dose of $100 \mathrm{mg} / \mathrm{kg}$ body weight. Three rats were examined at post-first injection (PFI) weeks 1, 3, 5, 7, and 10. Six control rats received an equivalent volume of physiological saline in the same manner, and three rats were examined at 1 and 10 weeks after the first injection.

\section{Immunohistochemical analysis}

All rats were euthanatized under ether anesthesia. The removed livers were fixed in $10 \%$ neutral buffered formalin ( $\mathrm{pH}$ 7.4), embedded in paraffin and sectioned. Deparaffinized tissue sections were analyzed immunohistochemically using a Labeled Histofine Simple Stain Kit (Nichirei, Tokyo, Japan), as described previously ${ }^{9,10}$. The following pretreatments were made; sections for antibodies to desmin (1:200 in dilution), vimentin $(1: 100)$, and GFAP $(1: 300)$ were treated with microwave for $5 \mathrm{~min}$, and those for $\alpha$-SMA $(1: 100)$ were treated with $0.1 \%$ trypsin for $10 \mathrm{~min}$ at $37^{\circ} \mathrm{C}$. The monoclonal (desmin, vimentin, and $\alpha$-SMA) and polyclonal (GFAP) antibodies were obtained from Dako Corp.
(Carpenteria, CA, USA). After treatments with $3 \% \mathrm{H}_{2} \mathrm{O}_{2}$ in phosphate buffered saline (PBS) for $10 \mathrm{~min}$ to quench endogenous peroxidase and then with 5\% skimmed milk in PBS for $30 \mathrm{~min}$ to inhibit non-specific reactions, the sections were incubated with primary antibody for $14 \mathrm{~h}$ at $4^{\circ} \mathrm{C}$, followed by the application of the reagent (labeled polymer) for $30 \mathrm{~min}$. Positive reactions were visualized with 3,3'diaminobenzidine. Sections were counterstained lightly with hematoxylin. As negative controls, tissue sections were treated with mouse or rabbit non-immune serum instead of the primary antibody.

Cells showing a distinct immunopositive-reaction for desmin, vimentin, GFAP, and $\alpha$-SMA were counted in five randomly selected areas $\left(0.0625 \mathrm{~mm}^{2} /\right.$ area $)$ in the perivenular area of hepatic lobules at a magnification of $\times 400^{9,10}$ : the areas most affected by TAA both in AHF and CHF. The mean values were calculated at each examination point.

\section{$R T-P C R$}

Total RNA was extracted from fresh liver tissues by homogenization with Trizol Reagent ${ }^{\mathrm{TM}}$ (Invitrogen Corp., Carlsbed, CA, USA). The RNA was reverse-transcribed to cDNA using Super Script Preamplification System ${ }^{\mathrm{TM}}$ (Invitrogen Corp., Carlsbed, CA, USA). cDNA was amplified by PCR with Taq DNA polymerase (TaKaRa Shuzo, Otsu, Japan) and each of the specific primers for rat NGF or $\beta$-actin (control). The following conditions were used for the amplification: 25 cycles of $30 \mathrm{sec}$ of denaturation at $94^{\circ} \mathrm{C}, 30 \mathrm{sec}$ of annealing at $55^{\circ} \mathrm{C}$, and $1 \mathrm{~min}$ of synthesis at $72^{\circ} \mathrm{C}$. The oligonucleotides used were as follows: for $\mathrm{NGF}$, sense primer 5'-AAGCGCTCAT CCACCCACCCAGTC-3' and antisense primer 5'CTCCTGCTTGCTGATCCACAT-3': for $\beta$-actin, sense primer 5'-TAAAGACCTCTATGCCAACAC-3' and antisense primer 5'-CTCCTGCTTGCTGATCCACAT-3 ${ }^{\prime 15}$. The PCR products were subjected to electrophoresis in a $2 \%$ agarose gel. The bands were semiquantitatively evaluated with image analysis software (NIH Image 1.61, Bethesda, MD, USA). The RT-PCR was done in triplicate using samples from each examination point.

\section{Results}

Histopathological characteristics of the AHF and CHF models were described in our previous papers ${ }^{9,10}$. The characteristics as observed in the present study are briefly described below.

\section{AHF}

Hepatocyte degeneration/necrosis induced by TAA occurred mainly in the perivenular areas of hepatic lobules as early as PSI days 1 and 3 (Fig. 1a), and simultaneously, the fibrotic lesions began to develop in the damaged areas on day 1 , and peaked on day 5 . Thereafter, the fibrotic areas gradually decreased on PSI days 7 (Fig. 1b) to 10, and the affected areas were replaced by regenerated hepatocytes on 

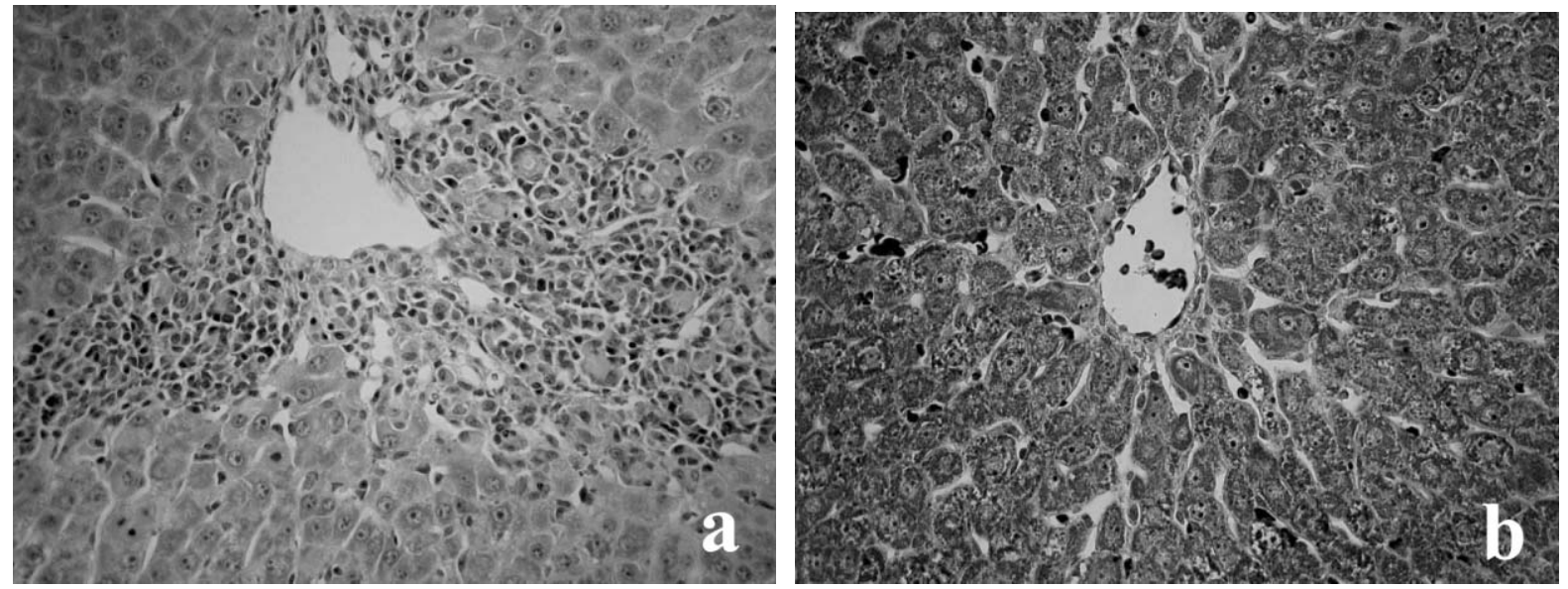

Fig. 1. Liver lesions on 3 days (a) and 7 days (b) after injection in the acute type hepatic fibrosis (AHF) model. Hepatocyte degeneration/necrosis with inflammatory cell reaction (mainly mononuclear cells) is seen in the perivenular areas of the hepatic lobule (a), and thereafter slight fibrosis developed (b). a, HE stain; b, Azan stain. a and $\mathbf{b}, \times 400$.
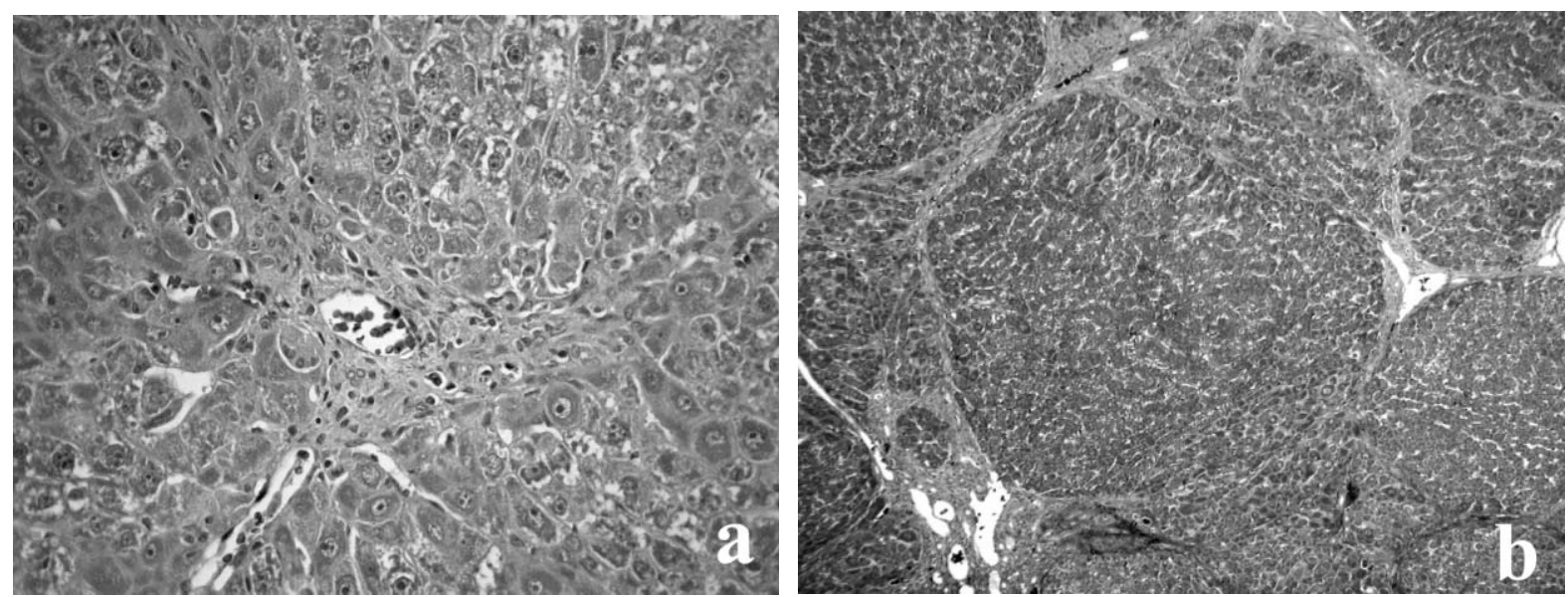

Fig. 2. Liver lesions at 5 weeks (a) and 10 weeks (b) after the initial injection in the chronic type hepatic fibrosis (CHF) model. Perivenular fibrosis following hepatocyte damage is seen (a), and at the advanced stages, micronodular lesions (pseudolobules) separated by fibrous septa developed (b). a, HE stain; b, Azan stain. a, $\times 400 ; \mathbf{b}, \times 150$.

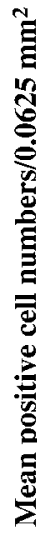

है
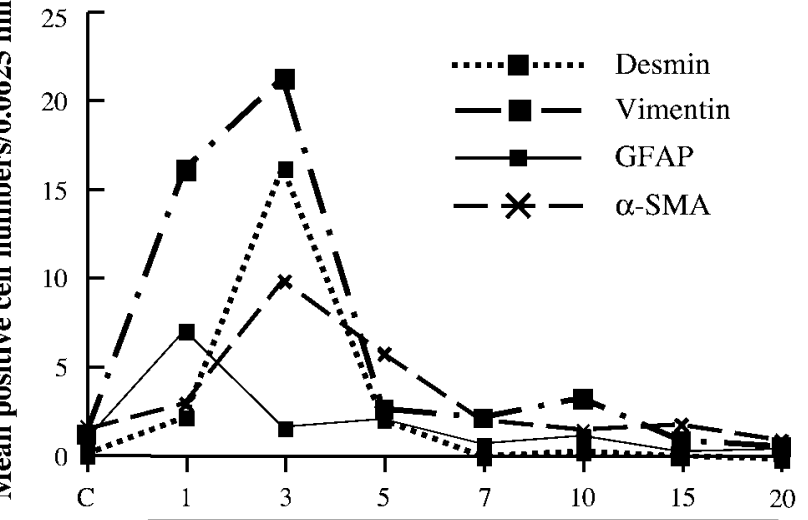

TAA-treatment (days)

Fig. 3. The kinetics of cells reacting with antibodies to desmin, glial fibrillary acidic protein (GFAP), vimentin and $\alpha$-smooth muscle actin ( $\alpha$-SMA) in the perivenular area in AHF. On day 3 , the vimentin-positive cells showed the greatest number among these immunophenotypical cells.

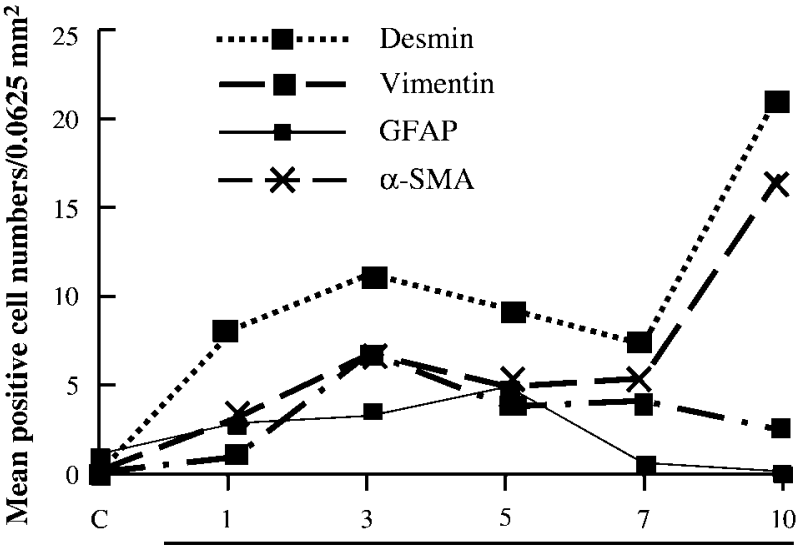

TAA-treatment (weeks)

Fig. 4. The kinetics of cells reacting with antibodies to desmin, GFAP, vimentin and $\alpha$-SMA in the perivenular area in CHF. Desmin-positive cells showed consistently the greatest number among these immunophenotypical cells. 

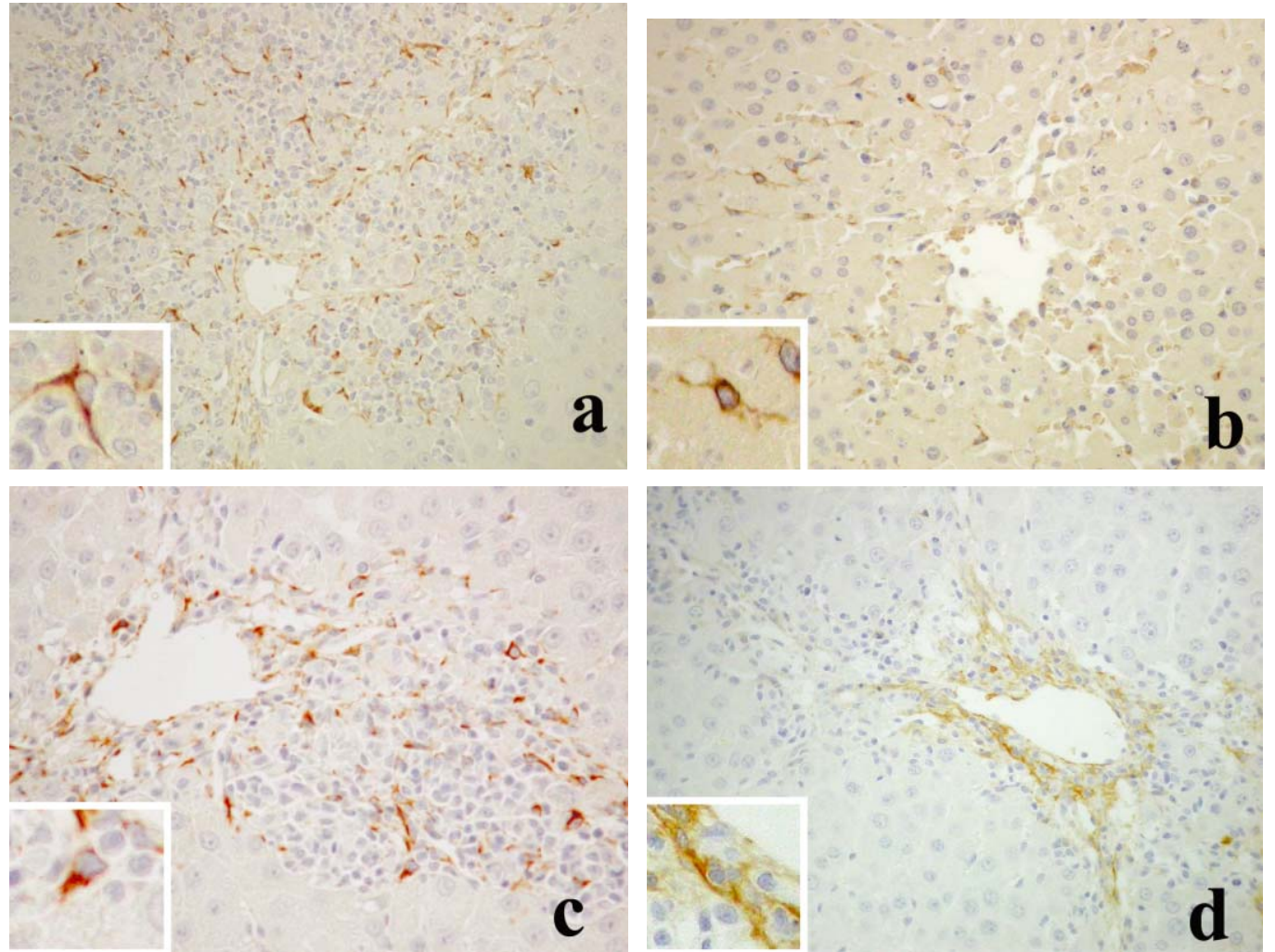

Fig. 5. Cells reacting with antibodies to desmin (a), GFAP (b), vimentin (c) and $\alpha$-SMA (d) in the perivenular area in AHF on 1 day (b) and 3 days $(\mathbf{a}, \mathbf{c}, \mathbf{d})$ after an injection. Desmin- and vimentin-positive cells are diffusely seen in the injured perivenular area, and GFAP-positive cells are sporadically present along sinusoids in the affected area. Alpha-SMA-positive cells are seen simply around the central vein. Morphologically, desmin-, GFAP-, and vimentin-positive cells are round or stellate in shape, whereas $\alpha$-SMA-positive cells show spindle or oval configurations. Immunohistochemistry: counterstained with hematoxylin, $\times 350$. Inset, positive cell of each immunophenotype, $\times 800$.
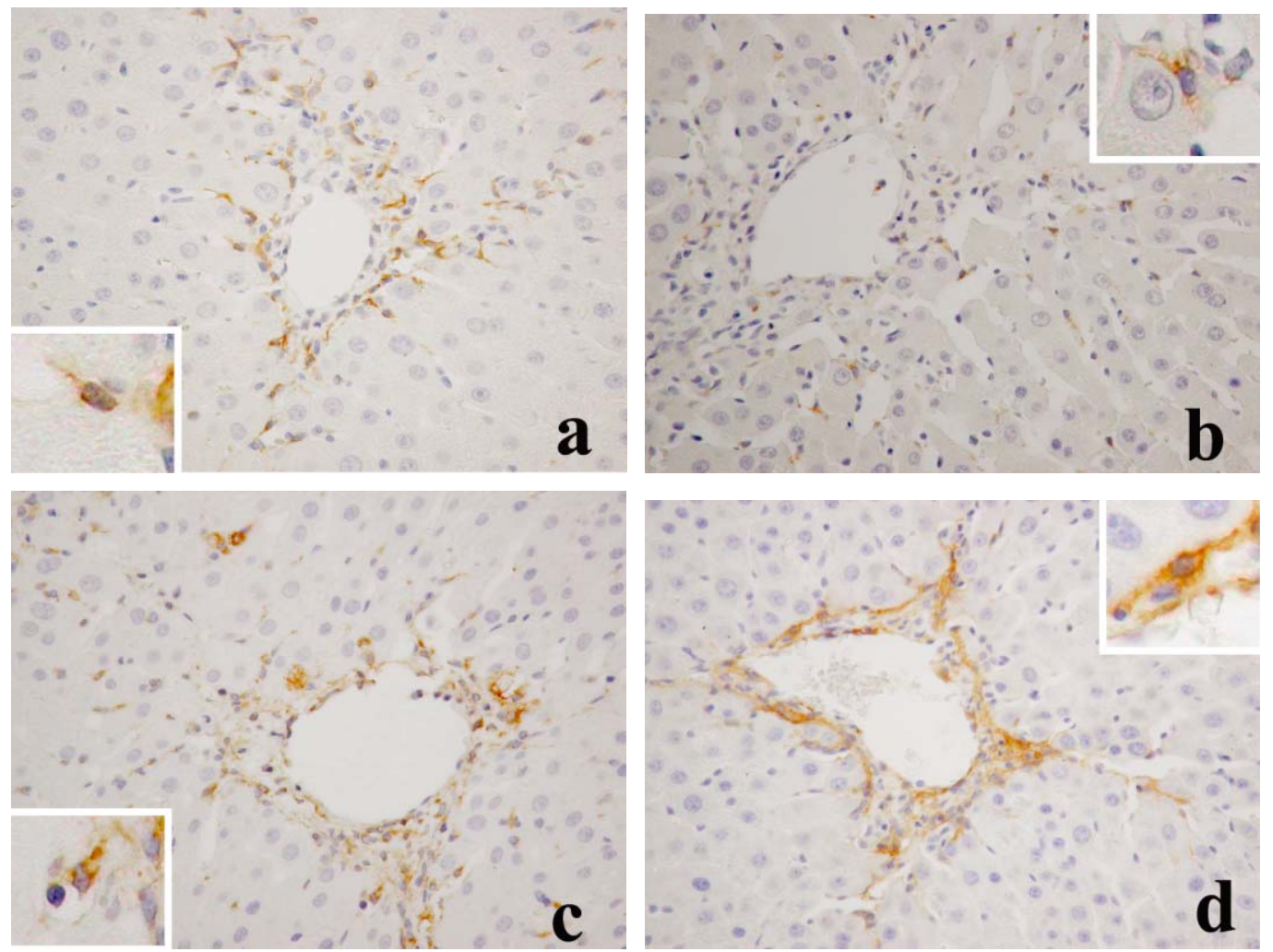
PSI days 15 to 20, indicating remodeling process.

\section{$\mathrm{CHF}$}

At PFI weeks 1, 3, and 5, hepatocyte degeneration became evident mainly in the perivenular and less frequently in the periportal areas, and thin fibrous septa were gradually formed between the central veins (Fig. 2a) and/or Glisson's sheath. At PFI weeks 10, micronodular lesions (psudolobules) separated by fibrous septa developed (Fig. $2 b$ ), indicating progressive hepatic fibrosis.

\section{Immunohistochemical analysis}

In control livers of both AHF and CHF, desmin-, $\alpha$ SMA-, GFAP- and vimentin-positive cells were rarely observed (Figs. 3 and 4).

Figure 3 shows the mean numbers of cells reacting to desmin, vimentin, GFAP and $\alpha$-SMA in the perivenular areas in AHF. The number of vimentin-positive cells was markedly increased as early as PSI day 1 , and showed the maximum on PSI day 3. Desmin- and $\alpha$-SMA-positive cells also reached the greatest number on PSI day 3. On PSI day 5 , the numbers of vimentin-, desmin-, and $\alpha$-SMA-positive cells quickly decreased, and on PSI day 7 and subsequent days, they retained low numbers less than 5 cells/area. Interestingly, GFAP-positive cell number showed a peak as early as PSI day 1, and thereafter, the number decreased; from PSI day 7 to day 20, positive cells were rarely seen.

The most frequent cells on PSI day 3 when hepatocyte injury in the perivenular areas was most prominent were vimentin-positive cells, followed by desmin-, $\alpha$-SMA-, and GFAP-positive cells. Desmin (Fig. 5a)-, GFAP (Fig. 5b)-, and vimentin (Fig. 5c)-positive cells were mainly round or stellate in shape, whereas $\alpha$-SMA-positive cells showed spindle or oval configurations (Fig. 5d). Vimentin- and desmin-positive cells were seen mainly in the injured perivenular areas (Fig. 5a, 5c), and $\alpha$-SMA-positive cells were exclusively localized around central veins (Fig. 5d). GFAP-positive cells were often seen along the sinusoids in and around the injured perivenular areas (Fig. 5b).

In $\mathrm{CHF}$, as shown in Fig. 4, the numbers of desmin-, vimentin-, and $\alpha$-SMA-positive cells gradually increased until PFI week 3; then, these numbers decreased until PFI week 7, but did not return to control levels. At PFI week 10 when micronodular lesions were completely formed, the numbers of desmin- and $\alpha$-SMA-positive cells again increased markedly, whereas the vimentin-positive cell number remained decreased. Although the number of GFAP-positive cells was small, it gradually increased until PFI week 5; at PFI weeks 7 and 10, GFAP-positive cells were rarely seen, similar to control livers. In CHF, desminpositive cells were consistently the most frequent cells during the 10-week observation period. The morphological characteristics of desmin (Fig. 6a)-, GFAP (Fig. 6b)-, vimentin (Fig. 6c)-, and $\alpha$-SMA (Fig. 6d)-positive cells seen in $\mathrm{CHF}$ were generally similar to those in AHF. Interestingly, the cytoplasm of $\alpha$-SMA-positive cells was more abundant than that of other immunophenotypic cells, and thus, $\alpha$-SMA-positive cells were the largest in size among these immunophenotypic cells. While GFAPpositive cells were seen along sinusoids in fibrotic perivenular areas (Fig. 6b), cells positive to desmin (Fig. 6a), vimentin (Fig. 6c) and $\alpha$-SMA (Fig. 6d) were seen mainly around the central veins in the fibrotic areas.

Comparing between AHF and CHF, the greatest expression in number among the immunophenotypic cells was vimentin in $\mathrm{AHF}$, whereas that was desmin in $\mathrm{CHF}$ (Figs. 3 and 4).

\section{$R T-P C R$}

In AHF, NGF mRNA expression was increased as early as PSI days 1 and 3, and on PSI day 5 and subsequent days the level was more than 2.5 folds greater than controls (Fig. 7). In CHF, NGF mRNA expression was about 2 folds greater than that of controls as early as PFI week 1 , and the higher expression was maintained until PFI week 10 (Fig. 8).

\section{Discussion}

As described in our previous paper on $\mathrm{AHF}^{10}$, TAAinduced initial lesions were seen mainly in the perivenular areas on PSI days 1 and 3, and then fibrotic lesions gradually developed in the perivenular areas until PSI day 5; thereafter, the lesions were repaired until PSI day 20, being accompanied with a decreased number of myofibroblasts. In $\mathrm{CHF}$, the repeated injection of TAA induced hepatocyte injury mainly in the perivenular areas and then in the periportal areas, and thus, fibrous septa were gradually formed until PFI week 7. As described in our previous paper $^{9}$, at PFI week 10, micronodules (pseudolobules) separated by fibrous septa were completely formed, indicating cirrhotic lesions. In the present study, the immunophenotypical changes of HSCs appearing in the early stages of fibrosis in the AHF model or in the developing fibrotic lesions (cirrhosis) in the CHF model were analyzed by immunoexpression of cytoskeletons. These AHF and CHF models are useful experimental tools for the development of myofibroblasts in hepatic fibrosis.

Myofibroblasts have been reported to play a role in

Fig. 6. Cells reacting with antibodies to desmin (a), GFAP (b), vimentin (c) and $\alpha$-SMA (d) in the perivenular area in CHF at 3 weeks after the initial injection. While GFAP-positive cells are present along sinusoids in the fibrotic area, cells positive to desmin, vimentin and $\alpha$-SMA are seen around the central vein in the fibrotic area. Morphological characteristics of desmin-, GFAP-, vimentin-, and $\alpha$-SMA-positive cells seen in CHF are generally similar to those in AHF. The cytoplasm of $\alpha$-SMA-positive cells appears to be more abundant than that of the other immunophenotypic cells. Immunohistochemistry: counterstained with hematoxylin, $\times 350$. Inset, positive cell of each immunophenotype, $\times 800$. 


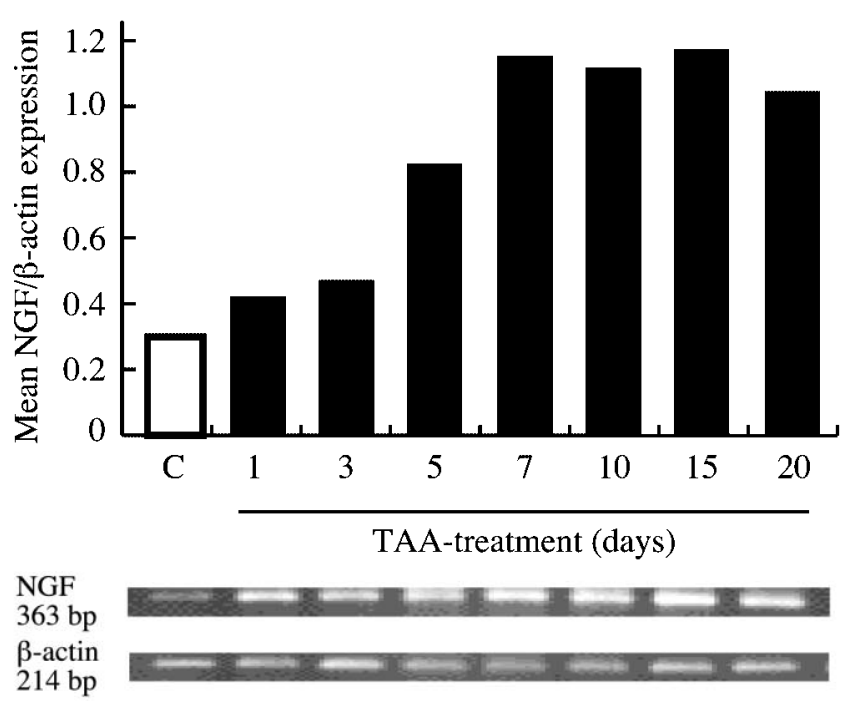

Fig. 7. The expression of NGF mRNA in AHF by RT-PCR. The expression level of NGF mRNA is normalized semiquantitatively by that for $\beta$-actin. C, control samples.

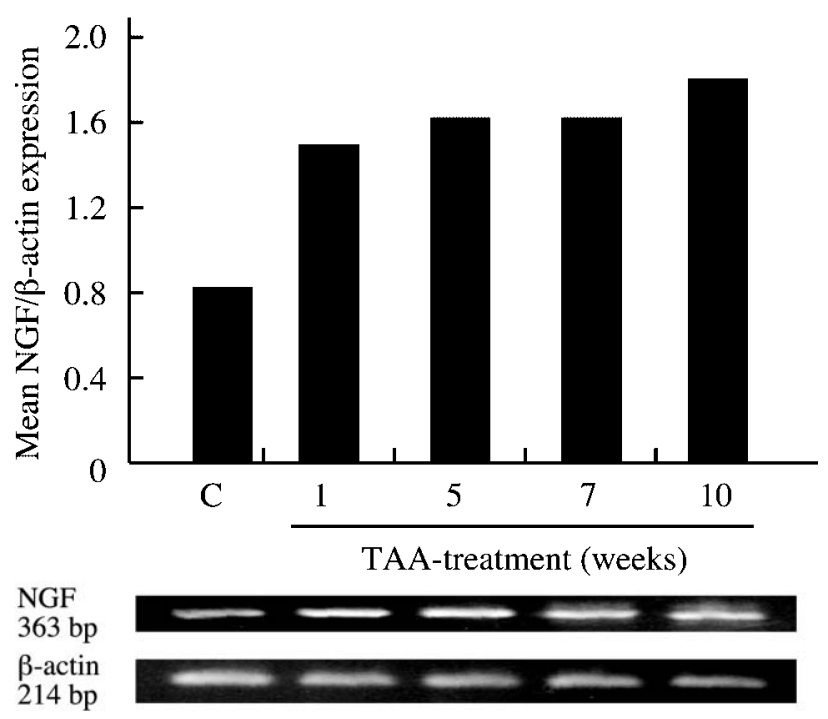

Fig. 8. The expression of NGF mRNA in CHF by RT-PCR. The expression level of NGF mRNA is normalized semiquantitatively by that for $\beta$-actin. $\mathrm{C}$, control samples. fibrogenesis of skin wound repair, as well as of the liver, kidney and lung, because they produce extracellular matrices (ECMs) such as collagens and fibronectin ${ }^{1,4}$. The derivation of myofibroblasts from pre-existing fibroblasts seems established in skin wound healing ${ }^{16-18}$. Interestingly, regenerating renal tubular epithelial cells in renal interstitial fibrosis may transdifferentiate into myofibroblasts ${ }^{19-21}$. HSCs and pancreatic stellate cells are also considered to be the major origin of hepatic and pancreatic fibrosis, respectively ${ }^{22,23}$. In addition, submesothelial stromal cells, ovarian thecal cells, pericytes and macrophages have been proposed as cells capable of expressing myofibroblastic phenotypes ${ }^{5,24-26}$. The myofibroblasts appear to be mysterious cells regarding their origin, but generally they have been identified by immunohistochemistry with an $\alpha$ SMA antibody ${ }^{6,18}$. Along with $\alpha$-SMA, vimentin and desmin might be cytoskeletons expressed in developing myofibroblasts ${ }^{5,6}$.

This study demonstrated that myofibroblasts appearing in rat $\mathrm{AHF}$ and $\mathrm{CHF}$ models showed various cytoskeletons such as vimentin, desmin, and $\alpha$-SMA ${ }^{4,27,28}$. In addition, it was shown that GFAP was expressed in myofibroblasts appearing in both AHF and CHF. Recently, several markers for neural/neuroectodermal differentiation, such as GFAP, nestin, synaptophysin, and the neural cell adhesion molecule, have been found to be expressed in transformed $\mathrm{HSCs}^{3,8,29,30}$. These findings suggest that HSCs might be differentiated ontogenetically from neural/neuroectodermal tissues in the ectodermal layer ${ }^{31}$. It will be interesting to pursue the relationship between transformed HSCs/ myofibroblastic cells and neural tissue-derived cells.

It is worth noting that there were differences in the immunophenotype kinetics between the cytoskeletons examined here, or between AHF and CHF. In AHF, the number of vimentin-, desmin-, and $\alpha$-SMA-positive cells showed the highest level on PSI day 3 , whereas that of GFAP-positive cells reached a plateau as early as PSI day 1. In CHF, $\alpha$-SMA- and desmin-positive cells showed similar kinetics to each other; their number gradually increased from PFI weeks 1 to 7 and then expanded quickly at PFI week 10 . On the other hand, the number of vimentin- and GFAPpositive cells did not increase even at PFI weeks 7 and 10 when pseudolobules were being formed. In comparisons between AHF and CHF, the greatest expression in the positive cell number among these cytoskeletons was vimentin in AHF, whereas it was desmin in CHF. These findings suggest that cytoskeletons expressed in rat hepatic myofibroblasts might depend on microenvironmental conditions evoked presumably by cell-cell and cell-matrix interactions, because such conditions would differ between AHF (fibrosis and subsequent healing) and $\mathrm{CHF}$ (progressive fibrosis leading to cirrhosis). It has been reported the in fibrotic lesions, inflammatory factors such as transforming growth factor- $\beta$, platelet-derived growth factor and tumor necrosis factor- $\alpha$ take part in the development of myofibroblasts ${ }^{17,32-34}$. The association of expressed cytoskeletons with such cytokines should be investigated in future studies.

Additionally, the RT-PCR methods demonstrated that NGF mRNA expressions markedly increased with time in both AHF and CHF. NGF is a neurotrophic protein essential for the maintenance, growth, and differentiation of nervous tissues, and NGF is also considered to be related to induction of apoptosis for HSCs ${ }^{11,13,14}$. The functions of NGF are induced through p 75 expressed on neural cells and Schwann cells $^{12,13}$. Recently, it was reported that HSC-derived myofibroblasts appearing in hepatic fibrosis expressed $\mathrm{p} 75$. Thus, they might respond to NGF stimulation, leading to 
their apoptosis as a result ${ }^{13}$. In AHF, the injured perivenular areas were repaired until PSI day 20 with a decreased number of myofibroblasts. Cirrhotic lesions developed in $\mathrm{CHF}$ are characterized by reconstruction of micronodules in which degeneration and regeneration of parenchymal cells and non-parenchymal cells repeatedly occur. Apoptosis might have been involved in such remodeling processes in $\mathrm{AHF}$ and $\mathrm{CHF}^{33-35}$. Although the biological significance of NGF remains to be investigated, the time-dependent increase of NGF mRNA might have been related to the remodeling or reconstruction of injured liver by regulating the transformed HSCs with p75.

In conclusion, the present study showed that transformed HSCs-derived myofibroblasts, appearing in rat hepatic fibrosis, expressed various cytoskeletons such as vimentin, desmin, $\alpha$-SMA, and GFAP in varying degrees, and that there were differences in the expression kinetics between AHF and CHF. In addition, NGF mRNA expression markedly increased with time in both AHF and CHF, as detected by RT-PCR methods, suggesting that NGF might regulate the development of HSCs with its receptor. Hepatic fibrosis is formed by complicated mechanisms still unknown, and further investigations are needed to understand the development and functional roles of HSCderived myofibroblasts.

Acknowledgments: This work was supported by Grants-inAid (No. 15380217 to J. Yamate, Scientific Research B, and No. 00347 to M. Ide, Young Generation Promotion Research) from Japan Society for the Promotion of Science (JSTP).

\section{References}

1. Friedman SL. Molecular regulation of hepatic fibrosis, an integrated cellular response to tissue injury. J Biol Chem 2000; 28: 2247-2250.

2. Tsutsumi M, Takada A, and Takase S. Characterization of desmin-positive rat liver sinusoidal cells. Hepatology 1987; 7: 277-284.

3. Knittel T, Aurisch S, Neubauer K, Eichhorst S, and Ramadori G. Cell-type specific expression of neural cell adhesion molecule (N-CAM) in Ito cells of rat liver: upregulation during in vitro activation and in hepatic tissue repair. Am J Pathol 1996; 149: 449-462.

4. Tuchweber B, Desmoulière A, Costa AMA, Yousef IM, and Gabbiani G. Myofibroblastic differentiation and extracellular matrix deposition in early stage of cholestatic fibrosis in the rat liver. Curr Top Pathol 1999; 93: 103-109.

5. Sappino AP, Schurch W, and Gabbiani G. Differentiation repertoire of fibroblastic cells: expression of cytoskeletal protein as marker of phenotypic modulations. Lab Invest 1990; 63: 144-161.

6. Desmoulière A, Daby IA, and Gabbiani G. Normal and pathologic soft tissue remodeling: role of the myofibroblast, with special emphasis on liver and kidney fibrosis. Lab Invest 2003; 83: 1689-1707.

7. Burt AD, Robertson JL, Heir J, and MacSween RN. Desmincontaining stellate cells in rat liver: distribution in normal animals and response to experimental acute liver injury. J Pathol 1986; 150: 29-35.

8. Neubauer K, Knittel T, Aurisch S, Fellmer P, and Ramadori G. Glial fibrillary acidic protein: a cell type specific marker for Ito cells in vivo and in vitro. J Hepatol 1996; 24: 719730 .

9. Ide M, Yamate J, Machida Y, Sawamoto O, Nakanishi M, Kuwamura M, Kotani T, and Sakuma S. Macrophage populations, myofibroblastic cells, and extracellular matrix accumulation in chronically-developing rat liver cirrhosis induced by repeated injection of thioacetamide. J Toxicol Pathol 2002; 15: 19-29.

10. Ide M, Yamate J, Machida Y, Nakanishi M, Kuwamura M, Kotani T, and Sawamoto O. Emergence of different macrophage populations in hepatic fibrosis following thioacetamide-induced acute hepatocyte injury in rats. $J$ Comp Pathol 2003; 128: 41-51.

11. Levi-Montalcini R. The nerve growth factor 35 years later. Science 1987; 4: 1154-1162.

12. Hirata H, Hibasami H, Yoshida T, Ogawa M, Matsumoto M, Morita A, and Uchida A. Nerve growth factor signaling of p75 induces differentiation and ceramide-mediated apoptosis in Schwann cells cultured from degenerating nerves. Glia 2001; 36: 245-258.

13. Trim N, Morgan S, Evans M, Issa R, Fine D, Afford S, Wilkins B, and Iredale J. Hepatic stellate cells express the low affinity nerve growth factor receptor $\mathrm{p} 75$ and undergo apoptosis in response to nerve growth factor stimulation. Am J Pathol 2000; 156: 1235-1243.

14. Oakley F, Trim N, Constandinou CM, Ye W, Gray AM, Frantz G, Hillan K, Kendall T, Benyon RC, Mann DA, and Iredale JP. Hepatocytes express nerve growth factor during liver injury: evidence for paracrine regulation of hepatic stellate cell apoptosis. Am J Pathol 2003; 163: 1849-1858.

15. Tsujino K, Yamate J, Tsukamoto Y, Kumagai D, Kannan Y, Jippo T, Kuwamura M, Kotani T, Takeya M, and Sakuma S. Establishment and characterization of cell lines derived from a transplantable rat malignant meningioma: morphological heterogeneity and production of nerve growth factor. Acta Neuropathol 1997; 93: 461-470.

16. Vande Berg JS, Rudolph R, Poolman WL, and Disharoon $\mathrm{DR}$. Comparative growth dynamics and actin concentration between cultured human myofibroblasts from granulating wounds and dermal fibroblasts from normal skin. Lab Invest 1989; 61: 532-538.

17. Pierce GF, Vande Berg JS, Rudolph R, Tarpley J, and Mustoe TA. Platelet-derived growth factor-BB and transforming growth factor beta 1 selectively modulate glycosaminoglycans, collagen, and myofibroblasts in excisional wounds. Am J Pathol 1991; 138: 629-646.

18. Desmoulière A, Redard M, Darby I, and Gabbiani G. Apoptosis mediates the decrease in cellularity during the transition between granulation tissue and scar. Am J Pathol 1995; 146: 56-66.

19. Ng YY, Huang TP, Yang WC, Chen ZP, Yang AH, Mu W, Nikolic-Paterson DJ, Atkins RC, and Lan HY. Tubular epithelial-myofibroblast transdifferentiation in progressive tubulointerstitial fibrosis in 5/6 nephrectomized rats. Kidney Int 1998; 54: 864-876.

20. Fan JM, Ng YY, Hill PA, Nikolic-Paterson DJ, Mu W, Atkins RC, and Lan HY. Transforming growth factor- $\beta$ regulates tubular epithelial-myofibroblast 
transdifferentiation in vitro. Kidney Int 1999; 56: 14551467.

21. Yang $\mathbf{J}$ and Liu Y. Dissection of key events in tubular epithelial to myofibroblast transition and its implications in renal interstitial fibrosis. Am J Pathol 2001; 159: 14651475.

22. Hines JE, Johnson SJ, and Burt AD. In vivo responses of macrophages and perisinusoidal cells to cholestatic liver injury. Am J Pathol 1993; 142: 511-518.

23. Haber PS, Keogh GW, Apte MV, Moran CS, Stewart NL, Crawford DH, Pirola RC, McCaughan GW, Ramm GA, and Wilson JS. Activation of pancreatic stellate cells in human and experimental pancreatic fibrosis. Am J Pathol 1999; 155: $1087-1095$.

24. Gown AM. The mysteries of the myofibroblast (partially) unmasked. Lab Invest 1990; 63: 1-3.

25. Bhawan J and Majno G. The myofibroblast: possible derivation from macrophages in xanthogranuloma. Am J Dermatopathol 1989; 11: 255-258.

26. Yamate J, Maeda M, Benn SJ, Laithwaite JE, Allan A, Ide M, Kuwamura M, Kotani T, Sakuma S, and LaMarre J. Differential effects of transforming growth factor- $\beta 1$, a fibrogenic factor, on macrophage-like cells (HS-P) and myofibroblastic cells (MT-9) in vitro. Toxicol Pathol 2001; 29: 483-491.

27. Friedman SL. Cytokines and fibrogenesis. Semin Liver Dis 1999; 19: 129-140.

28. Schuppan D, Cho JJ, Jia JD, and Hahn EG. Interplay of matrix and myofibroblasts during hepatic fibrogenesis. Curr
Top Pathol 1999; 93: 205-215.

29. Cassiman D, Van Pelt J, De Vos R, Van Lommel F, Desmet V, Yap S H, and Roskams T. Synaptophysin: a novel marker for human and rat hepatic stellate cells. Am J Pathol 1999; 155: $1831-1839$.

30. Niki T, De Bleser PJ, Xu G, Van Den Berg K, Wisse E, and Geerts A. Comparison of glial fibrillary acidic protein and desmin staining in normal and $\mathrm{CCl}_{4}$-induced fibrotic rat livers. Hepatology 1996; 3: 1538-1545.

31. Morrison SJ, White PM, Zock C, and Anderson DJ. Prospective identification, isolation by flow cytometry, and in vivo self-renewal of multipotent mammalian neural crest stem cells. Cell 1999; 96: 737-749.

32. Hellerbrand C, Stefanovic B, Giordano F, Burchardt ER, and Brenner DA. The role of TGF-betal in initiating hepatic stellate cell activation in vivo. J Hepatol 1999; 30: 77-87.

33. Gressner AM. The cell biology of liver fibrogenesis: an imbalance of proliferation, growth arrest and apoptosis of myofibroblasts. Cell Tissue Res 1998; 292: 447-452.

34. Saile B, Matthes N, Knittel T, and Ramadori G. Transforming growth factor beta and tumor necrosis factor alpha inhibit both apoptosis and proliferation of activated rat hepatic stellate cells. Hepatology 1999; 30: 196-202.

35. Ledda-Columbano GM, Coni P, Curto M, Giacomini L, Faa $\mathrm{G}$, Oliverio S, Piacentini M, and Columbano A. Induction of two different modes of cell death, apoptosis and necrosis, in rat liver after a single dose of thioacetamide. Am J Pathol 1991; 139: 1099-1109. 